Editorial

\title{
Introduction to the special issue of the Journal of Molecular Liquids "Supercritical fluids. Theory and applications" dedicated to Prof. Yu. E. Gorbaty
}

\author{
Abdenacer Idrissi $^{\mathrm{a}, *}$, Mikhail G. Kiselev ${ }^{\mathrm{b}}$, Andrey G. Kalinichev ${ }^{\mathrm{c}}$ \\ ${ }^{a}$ Université des Sciences et Technologies de Lille, France \\ ${ }^{\mathrm{b}}$ Institute of Solution Chemistry of the Russian Academy of Sciences, Ivanovo, Russia \\ ${ }^{c}$ Laboratoire SUBATECH (UMR 6457), Institut Mines-Télécom Atlantique, Nantes, France
}

Professor Yuri E. Gorbaty was born 30 July 1932 in the city Grozny, in the Soviet Union. He has graduated from the Mendeleev Institute of Chemical Technology, Moscow, in 1955. He has got his Candidate of Sciences (Ph.D.) degree in 1963 for his work on "Non-equilibrium crystallization of the three-component melts", and later in 1988 he was awarded a Doctor of Sciences degree for the work "The effect of temperature and pressure on the nearest ordering in liquid and supercritical water". Between these two dates and then later in his scientific career Yuri E. Gorbaty has become one of the leading experts in the field of experimental studies of the structure and properties of fluids, especially aqueous fluids at high temperatures and pressures, by methods of IR and Raman spectroscopy and by X-ray diffraction.

The uniqueness of his approach to the studies of hydrothermal solutions was in the simultaneous application of several complementary methods to investigate the same object under the same set of thermodynamic conditions. He has devoted a lot of efforts to develop a range of very original and sophisticated experimental optical and X-ray diffraction cells that could reliably withstand extreme conditions of hydrothermal experiments, while still allowing optical and X-ray access to the fluid sample inside through very cleverly designed and carefully sealed windows $[2,13,18,24-27,29,38,46]$. Particularly interesting and effective is the IR cell, the thickness of the absorbing layer in which can vary within a range of $0-1.5 \mathrm{~mm}$ directly during the experiment at high temperatures (up to $550{ }^{\circ} \mathrm{C}$ ) and pressures (up to 1500 bars) with an accuracy of $\pm 0.5 \mu \mathrm{m}$ [24]. In the cell for Raman spectroscopy with internal vessels, the fluid sample only contacts with sapphire and gold, which avoids any interaction of the metal walls of the high-pressure cell with highly corrosive supercritical solutions [45]. Cells for energy dispersive X-ray diffractometry, UV spectroscopy and many other devices were also created for

\footnotetext{
* Corresponding author.

Email address: nacer.idrissi@univ-lille1.fr (A. Idrissi)
}

conducting physical experiments at high temperatures and pressures $[27,46]$.

The most valuable data were obtained by measuring the intensity of X-ray scattering from water up to $t=550{ }^{\circ} \mathrm{C}$ and $P=1000$ bar and up to 8000 bar at room temperature and for the first time extracting experimental information about molecular pair correlation functions of water under these extreme conditions [14-17,19,20,28]. These data were complemented by the results of studies using infrared absorption spectroscopy and Raman scattering [4-5,8-9,23,31,38-39].

$\mathrm{Yu}$.E. Gorbaty proposed a new approach to the description of the structure of liquid and supercritical water, based on the percolation theory. It was shown that the liquid and supercritical states differ qualitatively depending on the existence or absence of an infinite cluster of hydrogen-bonded molecules [33,34]. The percolation threshold for a three-dimensional network of hydrogen bonds in water is reached in the region of the critical isotherm. Below the percolation threshold, only clusters of finite size can exist in the supercritical region. This explains many interesting and still misunderstood phenomena that occur during the transition of a liquid to the supercritical state. One of the brilliant findings of Prof. Gorbaty together with his colleagues was the experimentally proven idea of universality of hydrogen bonding behavior of alcohols under supercritical conditions [44]. Until his last days, he was always full of new ideas, and was always ready to share them with his colleagues.

\section{Bibliography of Yuri Gorbaty's publications in chronological} order

[1] M.B. Epelbaum, Y.E. Gorbatyi, A technique for preparing glass specimens for the measurement of microhardness, Ind. Lab. 28 (12) (1962) 1595-1597.

[2] I.V. Babashov, G.V. Bondarenko, Y.E. Gorbatyi, M.B. Epelbaum, Cuvette for i spectroscopy of highly absorbing fluids at high pressures and temperatures, Instrum. Exp. Tech. USSR 2 (1970) 560-565.

[3] Y.E. Gorbaty, G.V. Bondarenko, Molecular Spectra of Water at High Temperatures and Pressures, In: Phase Equilibria and Mineral Formation Processes, Nauka, Moscow, 1973, pp. 207-230 (in Russian).

[4] G.V. Bondarenko, Y.E. Gorbatyi, Infrared-spectra $v_{3}$ of HDO under high-pressure and temperature, Dokl. Akad. Nauk SSSR 210 (1) (1973) 132-135. 
[5] G.V. Bondarenko, Y.E. Gorbatyi, V.M. Edelshtein, Effect of temperature and pressure on vibration-rotation spectra of water supercritical phase, Dokl. Akad. Nauk SSSR 214 (2) (1974) 365-368 (in Russian).

[6] G.V. Bondarenko, Y.E. Gorbatyi, G.A. Mishchenchuk, Some remarks concerning frequency of flat deformation vibrations of $\mathrm{X}-\mathrm{O}-\mathrm{X}$ groups in minerals and glasses - answers by Yukhnevich, GV and Akhmanova, MV, Geokhimiya 2 (1974) 321-325.

[7] M.B. Geilikman, Y.E. Gorbatyi, Anomalous character of internal-pressure of liquid water, J. Struct. Chem. 16 (6) (1975) 935-941.

[8] G.V. Bondarenko, Y.E. Gorbatyi, Analysis of contour of $v_{2}+v_{3}$ absorption-band in spectra of liquid $\mathrm{D}_{2} \mathrm{O}$ at temperatures from 20 to $350{ }^{\circ} \mathrm{C}$, J. Struct. Chem. 17 (6) (1976) 884-890.

[9] G.V. Bondarenko, Y.E. Gorbaty, Molecular Rotational and Vibrational Spectra of Deuterated Water at Pressures Up to 500 bar and Temperature Up to $550{ }^{\circ} \mathrm{C}$, In: Notices on Physico-Chemical Petrology, Nauka, Moscow, 1977, pp. 46-53 (in Russian).

[10] Y.E. Gorbaty, Some new Data on the Structure of Liquid and Supercritical Phases of Water, In: Problems of Physico-Chemical Petrology, Vol. II, Nauka, Moscow, 1979, pp. 15-24 (in Russian).

[11] Y.E. Gorbaty, Demyanets, Structure factor of liquid and supercritical water at a pressure of 1000 bar and temperatures from 298 to 773 K, Dokl. Akad. Nauk SSSR 260 (1) (1981) 911-915 (in Russian)

[12] Y. Gorbaty, An experimental-study of structure of liquid and supercritical water, Fortschr. Mineral. 60 (1982) 6-7.

[13] Y.E. Gorbatyi, I.V. Babashov, G.V. Bondarenko, A simple setup for changing the polarization of laser-radiation, Instrum. Exp. Tech. 25 (5) (1982) 215-216.

[14] Y.E. Gorbatyi, Y.N. Demyanets, , J. Struct. Chem. 23 (6) (1982) 882-894.

[15] Y.E. Gorbatyi, Y.N. Demyanets, X-ray-diffraction studies of the structure of liquid and supercritical water at high-temperatures and pressures. 2. The molecular density radial-distribution functions and the paired correlation-functions, J. Struct. Chem. 24 (3) (1983) 385-392.

[16] Y.E. Gorbatyi, Y.I. Demyanets, , J. Struct. Chem. 24 (5) (1983) 716-722.

[17] Y.E. Gorbaty, Y.N. Demianets, The pair-correlation functions of water at a pressure of 1000 bar in the temperature-range $25-500{ }^{\circ} \mathrm{C}$, Chem. Phys. Lett. 100 (5) (1983) 450-454.

[18] Y.E. Gorbatyi, G.V. Bondarenko, I.V. Babashov, A high-temperature high-pressure-cell for Raman-spectroscopy, Instrum. Exp. Tech. 27 (1) (1984) 208-210.

[19] Y.E. Gorbaty, Y.N. Demyanets, Effect of pressure on the short-range molecular ordering in liquid water, Dokl. Akad. Nauk SSSR 275 (4) (1984) 903-906 (in Russian).

[20] Y.E. Gorbaty, Y.N. Demianets, An X-ray study of the effect of pressure on the structure of liquid water, Mol. Phys. 55 (3) (1985) 571-588.

[21] Y.E. Gorbaty, Hydrothermal Fluid: Effects of Temperature and Pressure on the Structure of Water, In: Experiment in the Solution of Important Geological Problems, Nauka, Moscow, 1986, pp. 387-399 (in Russian).

[22] Y.E. Gorbaty, Capabilities of Diffraction Methods in the Studies of Aqueous Systems at High Temperatures and Pressures, In: Thermodynamic Properties of Solutions under Extreme Conditions, 1986, pp. Ivanovo Institute of Chemical Technology, Ivanovo, 83-91 (in Russian).

[23] G.V. Bondarenko, Y.E. Gorbaty, An infrared study of water-vapor in the temperature-range 573-723-K - dimerization enthalpy and absorption intensities for monomer and dimer, Mol. Phys. 74 (3) (1991) 639-647.

[24] Y.E. Gorbaty, G.V. Bondarenko, High-pressure, high-temperature 2-chamber cell with changeable path lengths for accurate measurements of absorption-coefficient, Rev. Sci. Instrum. 64 (8) (1993) 2346-2349.

[25] Y.E. Gorbaty, Reliable high-pressure seal for multiple applications, Rev. Sci. Instrum. 65 (2) (1994) 505-506.

[26] Y.E. Gorbaty, G.V. Bondarenko, S.T. Mileiko, Soldered high-pressure high-temperature sapphire window, Rev. Sci. Instrum. 65 (8) (1994) 2739-2740.

[27] Y.E. Gorbaty, A.V. Okhulkov, High-pressure X-ray cell for studying the structure of fluids with the energy-dispersive technique, Rev. Sci. Instrum. 65 (7) (1994) 2195-2198.

[28] A.V. Okhulkov, Y.N. Demianets, Y.E. Gorbaty, X-ray-scattering in liquid water at pressures of up to $7.7 \mathrm{kbar}$ - test of a fluctuation model, J. Chem Phys. 100 (2) (1994) 1578-1588.

[29] Y.E. Gorbaty, G.V. Bondarenko, High-pressure high-temperature Raman cell for corrosive liquids, Rev. Sci. Instrum. 66 (8) (1995) 4347-4349.

[30] Y.E. Gorbaty, A.G. Kalinichev, , J. Phys. Chem. 99 (15) (1995) 5336-5340

[31] G.V. Bondarenko, Y.E. Gorbaty, In situ Raman spectroscopic study of sulfur-saturated water at 1000 bar between 200 and $500{ }^{\circ} \mathrm{C}$, Geochim. Cosmochim. Acta 61 (7) (1997) 1413-1420.

[32] Yu.E. Gorbaty, A.G. Kalinichev, G.V. Bondarenko, Supercritical state and the structure of liquids, Priroda 8 (1997) 78-89 (in Russian).

[33] Y.E. Gorbaty, G.V. Bondarenko, The physical state of supercritical fluids, J. Supercrit. Fluids 14 (1) (1998) 1-8.
[34] Y.E. Gorbaty, R.B. Gupta, The structural features of liquid and supercritical water, Ind. Eng. Chem. Res. 37 (8) (1998) 3026-3035.

[35] A.G. Kalinichev, Yu.E. Gorbaty, Effect of Hydrogen Bonding on the Structure and Properties of Hydrothermal Fluids, In: Experimental and Theoretical Modeling of the Processes of Mineral Formation, Nauka, Moscow, 1998, pp. 242-264 (in Russian).

[36] G.V. Bondarenko, Yu.E. Gorbaty, Sulfur in Hydrothermal Fluid, In: Experimental and Theoretical Modeling of the Processes of Mineral Formation, M. Nauka, Moscow, 1998, pp. 393-408 (in Russian).

[37] Yu.E. Gorbaty, G.V. Bondarenko, The physical state of supercritical fluids, Exp. Geosci. 7 (1) (1998) 40

[38] Y.E. Gorbaty, G.V. Bondarenko, Experimental technique for quantitative IR studies of highly absorbing substances at high temperatures and pressures, Appl. Spectrosc. 53 (8) (1999) 908-913.

[39] Y.E. Gorbaty, G.V. Bondarenko, A.G. Kalinichev, A.V. Okhulkov, The effect of pressure on hydrogen bonding in water: IR study of v(OD) HDO at pressures of up to 1500 bar, Mol. Phys. 96 (11) (1999) 1659-1665.

[40] A.G. Kalinichev, Y.E. Gorbaty, A.V. Okhulkov, Structure and hydrogen bonding of liquid water at high hydrostatic pressures: Monte Carlo NPT-ensemble simulations up to $10 \mathrm{kbar}$, J. Mol. Liq. 82 (1-2) (1999) 57-72.

[41] Yu.E. Gorbaty, A model of liquid water transition into supercritical state, Exp. Geosci. 8 (1) (1999) 70-71.

[42] M. Poliakoff, S.J. Barlow, G.V. Bondarenko, Y.E. Gorbaty, FTIR reaction monitoring in alcohols and water up to $500{ }^{\circ} \mathrm{C}$ and 1000 bar, Abstr. Pap. Am. Chem. Soc. 220 (2000) U214-U215

[43] A.V. Okhulkov, Y.E. Gorbaty, The pair correlation functions of $1.1 \mathrm{M} \mathrm{NaCl}$ aqueous solution at a constant pressure of 1000 bar in the temperature range 20-500 ${ }^{\circ} \mathrm{C}$, J. Mol. Liq. 93 (1-3) (2001) 39-42.

[44] S.J. Barlow, G.V. Bondarenko, Y.E. Gorbaty, T. Yamaguchi, M. Poliakoff, An IR study of hydrogen bonding in liquid and supercritical alcohols, J. Phys. Chem. A 106 (43) (2002) 10452-10460.

[45] Y.E. Gorbaty, G.V. Bondarenko, E. Venardou, E. Garcia-Verdugo, M Sokolova, J. Ke, M. Poliakoff, High-pressure high-temperature Raman spectroscopy of liquid and supercritical fluids, Appl. Spectrosc. 57 (10) (2003) $1300-1303$.

[46] Y.E. Gorbaty, E. Venardou, E. Garcia-Verdugo, M. Poliakoff, High-temperature and high-pressure cell for kinetic measurements of supercritical fluids reactions with the use of ultraviolet-visible spectroscopy, Rev. Sci. Instrum. 74 (6) (2003) 3073-3076.

[47] Y.E. Gorbaty, G.V. Bondarenko, E. Venardou, S.J. Barlow, E. Garcia-Verdugo, M. Poliakoff, Experimental spectroscopic high-temperature high-pressure techniques for studying liquid and supercritical fluids, Vib. Spectrosc. 35 (1-2) (2004) 97-101.

[48] E. Venardou, E. Garcia-Verdugo, S.J. Barlow, Y.E. Gorbaty, M. Poliakoff, On-line monitoring of the hydrolysis of acetonitrile in near-critical water using Raman spectroscopy, Vib. Spectrosc. 35 (1-2) (2004) 103-109.

[49] G.V. Bondarenko, Yu.E. Gorbaty, A.G. Kalinichev, A.V. Okhulkov, A Comprehensive Study of Liquid and Supercritical Aqueous Electrolyte Solutions by Methods of Vibration Spectroscopy, X-ray Diffraction and Molecular Simulations, In: Experimental Mineralogy: Some Results on the Century's Frontier, Vol. 2, Nauka, Moscow, 2004, pp. 15-25 (in Russian).

[50] G.V. Bondarenko, Y.E. Gorbaty, A.V. Okhulkov, A.G. Kalinichev, Structure and hydrogen bonding in liquid and supercritical aqueous $\mathrm{NaCl}$ solutions at a pressure of 1000 bar and temperatures up to $500^{\circ} \mathrm{C}$ : a comprehensive experimental and computational study, J. Phys. Chem. A 110 (11) (2006) 4042-4052.

[51] A.G. Kalinichev, G.V. Bondarenko, Y.E. Gorbaty, R.J. Kirkpatrick, Structure and hydrogen bonding in hydrothermal $\mathrm{H}_{2} \mathrm{O}-\mathrm{NaCl}$ solutions: are IR and Raman vibrational spectra telling us the whole story?, Abstr. Pap. Am. Chem. Soc. $232(2006)$

[52] M. Sokolova, S.J. Barlow, G.V. Bondarenko, Y.E. Gorbaty, M. Poliakoff, Comparison between IR absorption and Raman scattering spectra of liquid and supercritical 1-butanol, J. Phys. Chem. A 110 (11) (2006) 3882-3885.

[53] Y.E. Gorbaty, G.V. Bondarenko, Experimental Studies of the Hydrothermal Fluid Structure, In: Experimental Studies of Endogene Processes, IEM RAS, Chernogolovka, 2008, pp. 124-140 (in Russian).

[54] E.G. Osadchii, Y.E. Gorbaty, Raman spectra and unit cell parameters of sphalerite solid solutions $\left(\mathrm{Fe}_{x} \mathrm{Zn}_{1-\mathrm{x}} \mathrm{S}\right)$, Geochim. Cosmochim. Acta 74 (2) (2010) $568-573$.

[55] G.V. Bondarenko, Y.E. Gorbaty, Hydrogen bonding in aqueous solution of Na$\mathrm{ClO}_{4}$, Mol. Phys. 109 (5) (2011) 783-788.

[56] K.I. Shmulovich, Y.E. Gorbaty, G.V. Bondarenko, Pressure dependence of the Raman spectra of aqueous solutions and anthracene, Russ. J. Phys. Chem. B 6 (8) (2012) 907-911.

[57] Y.E. Gorbaty, G.V. Bondarenko, Comparison of the sensitivities of IR absorption and raman scattering spectra to hydrogen bonding in methanol, Russ. J. Phys. Chem. B 6 (8) (2012) 873-877. 